\title{
Technical Note: Determination of aerosol optical properties by a calibrated sky imager
}

\author{
A. Cazorla ${ }^{1,2}$, J. E. Shields ${ }^{3}$, M. E. Karr ${ }^{3}$, F. J. Olmo ${ }^{3}$, A. Burden ${ }^{1,2}$, and L. Alados-Arboledas ${ }^{1,2}$ \\ ${ }^{1}$ Departamento de Física Aplicada, Facultad de Ciencias, Universidad de Granada, Fuentenueva s/n. 18071, Granada, Spain \\ ${ }^{2}$ Centro Andaluz de Medio Ambiente (CEAMA), Junta de Andalucía-Universidad de Granada, Avda. del Mediterraneo s/n. \\ 18071, Granada, Spain \\ ${ }^{3}$ Marine Physical Lab, Scripps Institution of Oceanography, University of California San Diego, 9500 Gilman Dr., La Jolla, \\ 92093-0701 CA, USA
}

Received: 27 August 2008 - Published in Atmos. Chem. Phys. Discuss.: 28 Noveember 2008

Revised: 17 March 2009 - Accepted: 6 July 2009 - Published: 8 September 2009

\begin{abstract}
The calibrated ground-based sky imager developed in the Marine Physical Laboratory, the Whole Sky Imager (WSI), has been tested with data from the Atmospheric Radiation Measurement Program (ARM) at the Southern Great Plain site (SGP) to determine optical properties of the atmospheric aerosol. Different neural network-based models calculate the aerosol optical depth (AOD) for three wavelengths using the radiance extracted from the principal plane of sky images from the WSI as input parameters. The models use data from a CIMEL CE318 photometer for training and validation and the wavelengths used correspond to the closest wavelengths in both instruments. The spectral dependency of the AOD, characterized by the Ångström exponent $\alpha$ in the interval $440-870 \mathrm{~nm}$, is also derived using the standard AERONET procedure and also with a neural network-based model using the values obtained with a CIMEL CE318. The deviations between the WSI derived AOD and the AOD retrieved by AERONET are within the nominal uncertainty assigned to the AERONET AOD calculation $( \pm 0.01)$, in $80 \%$ of the cases. The explanation of data variance by the model is over $92 \%$ in all cases. In the case of $\alpha$, the deviation is within the uncertainty assigned to the AERONET $\alpha( \pm 0.1)$ in $50 \%$ of the cases for the standard method and $84 \%$ for the neural network-based model. The explanation of data variance by the model is $63 \%$ for the standard method and $77 \%$ for the neural network-based model.
\end{abstract}

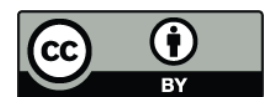

Correspondence to:

L. Alados-Arboledas (alados@ugr.es)

\section{Introduction}

Atmospheric aerosol interacts both directly and indirectly with the Earth's radiation budget and thus influences the climate. Directly, aerosol scatters and absorbs shortwave and longwave radiation, and indirectly, aerosol in the lower atmosphere modifies the microphysical and hence the radiative properties, amount and lifetime of clouds. In addition, aerosol absorption of shortwave and longwave radiation warms the aerosol layer modifying the relative humidity condition, which affects the process of cloud formation (the semi-direct effect) (Foster et al., 2007).

IPCC (IPCC, 2007) reported that the anthropogenic contributions to aerosol (primarily sulphate, organic carbon, black carbon, nitrate and dust) together produce a cooling effect, with a total direct radiative forcing of -0.5 [ -0.9 to $-0.1] \mathrm{W} \mathrm{m}^{-2}$ and an indirect cloud albedo forcing of -0.7 $[-1.8$ to -0.3$] \mathrm{W} \mathrm{m}^{-2}$ (Foster et al., 2007). This is comparable in magnitude to the forcing induced by the increase of the greenhouse effect gases concentration during the last century (Foster et al., 2007). However, radiative forcing induced by aerosol has a large uncertainty, and may thus have much more importance in the overall energy balance.

Knowledge of the parameters that determine the optical properties of atmospheric aerosol is essential for the determination of their climate effects (Kaufman et al., 2002). Nevertheless, there are many difficulties in evaluating the climate effects of the aerosol due to the great spatial and temporal variability of their concentrations and properties. In this sense long range transport events like Saharan dust outbreaks (Lyamani et al., 2005, 2006a, b) or global scale events like

Published by Copernicus Publications on behalf of the European Geosciences Union. 
stratospheric aerosols following major volcanic eruptions like El Chichón and Mount Pinatubo (Olmo and AladosArboledas, 1995) represent extreme cases of this variability. Remote sensing appears to be a valuable tool for characterizing the physical and optical properties of the aerosol. Sunphotometry is the most common way to characterize aerosol in daytime from the ground and several instruments and networks all over the world are used to characterize the atmospheric aerosol.

Ground-based sky imagery has been used for years for cloud cover assessment, e.g. Cazorla et al. (2008a), Long et al. (2006), Sabburg (2000) and Shields et al. (1998). Considering the increasing interest in automatic ground-based devices that provide cloud detection and characterization in near real time, this work contribute to the search of solutions that combine the cloud and aerosol in the same instrument. Previous work with the All-Sky Imager, a non-calibrated sky imager developed in the Atmospheric Physics Group (Centro Andaluz de Medio Ambiente, University of Granada, Spain), revealed the potential of the ground-based sky imagery for aerosol characterization (Cazorla et al., 2008b). By developing techniques to extract aerosol characteristics from sky imagers, we propose a value-added to the instrument and a complement to the existing aerosol data bases.

In this paper, the Whole Sky Imager (WSI), a calibrated ground-based sky imager, developed in the Atmospheric Optics Group (Marine Physical Laboratory, Scripps Institution of Oceanography, University of California San Diego) (AOG) has been tested to determine optical properties of the atmospheric aerosol. Different neural network-based models estimate the aerosol optical depth for three wavelengths using the radiance extracted from the principal plane of sky images from the WSI (i.e., at constant azimuth angle equal to the solar azimuthal angle, with varied zenithal angles) as input parameters. The Angström coefficients $\alpha$ and $\beta$ (Ångström, 1964) are also derived from the aerosol optical depth estimated with the models and a neural network-based model also estimates the Ångström exponent $\alpha$. The models use data from a CIMEL CE318 photometer (Holben et al., 1998) for training and validation.

\section{Site and instrument description}

\subsection{Experimental site}

This work is the result of cooperation between the Atmospheric Physics Group and the Atmospheric Optics Group. This last group has been researching and developing sky imagers for decades (Shields et al., 1998). They have different sky imagers in different locations. The WSI used in this work was located in the Southern Great Plain (SGP) in the United States during 2000-2004 (an earlier WSI was at the site from 1995-2000).

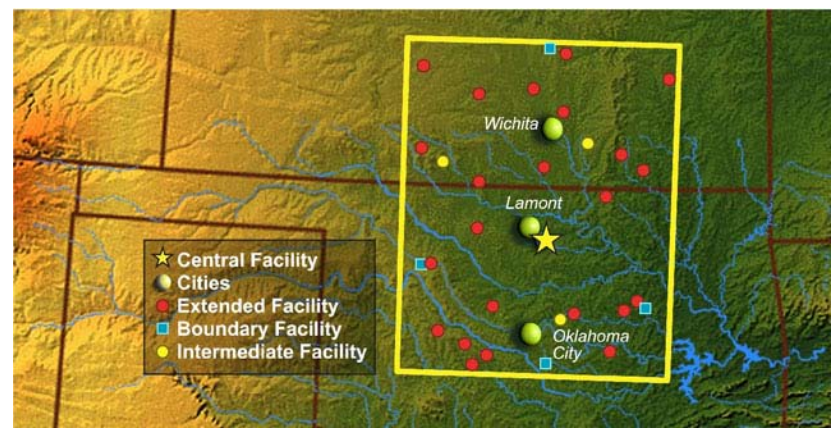

Fig. 1. SGP facility map (image from the ARM Program web site). Central facility geographical coordinates: $\left(36.61^{\circ} \mathrm{N}, 97.5^{\circ} \mathrm{W}\right.$, $320 \mathrm{~m}$ a.s.1.).

The SGP site was the first field measurement site established by the Department of Energy's (DOE) Atmospheric Radiation Measurement (ARM) Program (www.arm.gov). Scientists are using the information obtained from the SGP to improve cloud and radiative models and parameterizations and, thereby, the performance of atmospheric general circulation models used for climate research. The SGP site consists of in situ and remote-sensing instrument clusters arrayed across approximately 143,000 square kilometers in northcentral Oklahoma. Figure 1 shows a map of the facility. The central facility is a heavily instrumented location on 0.65 square kilometers of cattle pasture and wheat fields southeast of Lamont, Oklahoma ( $36.61^{\circ} \mathrm{N}, 97.5^{\circ} \mathrm{W}, 320 \mathrm{~m}$ a.s.1.). More than 30 instrument clusters have been placed around the SGP site, at the Central Facility and at Boundary, Extended, and Intermediate Facilities. The locations for the instruments were chosen so that the measurements reflect conditions over the typical distribution of land uses within the site.

Both instruments, the CIMEL CE318 and the WSI are located in the central facility.

\subsection{The sun-photometer CIMEL CE-318}

Sun photometry is the most widely used technique for atmospheric aerosol characterization in daytime. The CIMEL CE318 automatic sun tracking photometer (Holben et al., 1998) has been designed to measure sun and sky radiance in order to derive total column water vapor and aerosol properties using a combination of spectral filters and azimuth/zenith viewing controlled by a microprocessor.

The CIMEL CE318 is the standard instrument in the AERONET network (Holben et al., 1998). AERONET collaboration provides globally distributed observations of spectral AOD, inversion products (Dubovik et al., 2002, 2006) and precipitable water in diverse aerosol regimes. AOD data are computed for three data quality levels: Level 1.0 (unscreened), Level 1.5 (cloud-screened), and Level 2.0 (cloud screened and quality-assured). 


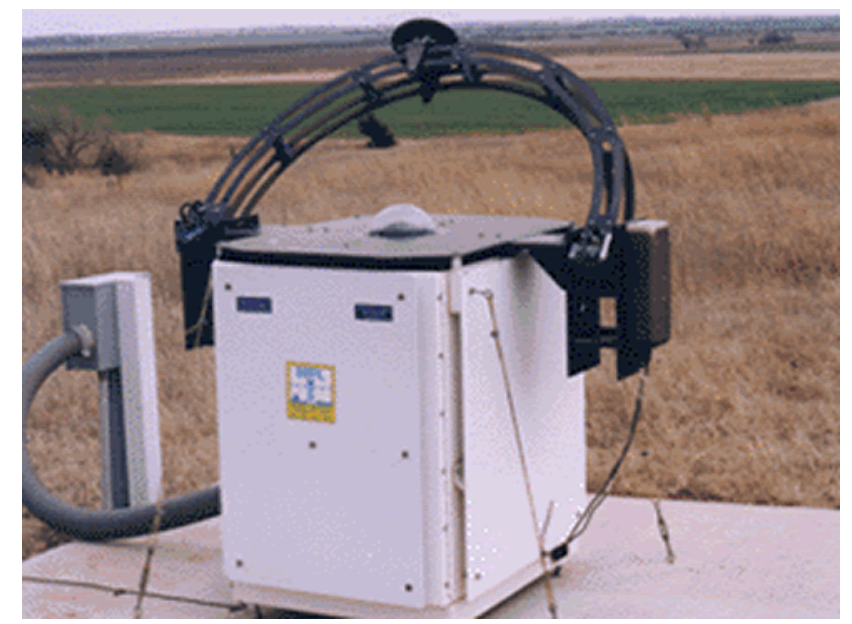

Fig. 2. Day/Night WSI fielded at SGP CART site.

The CIMEL CE318 used in this work has operated in the AERONET program since 1994. We use the level 2.0 data (quality-assured) and the parameters extracted are AOD at 440,675 and $870 \mathrm{~nm}$ and $\alpha$ in the interval $440-870 \mathrm{~nm}$.

\subsection{The Whole Sky Imager}

The Atmospheric Optics Group has been very active in the development of digital sky imager for over two decades. The original concept for the WSI evolved from a measurement and modeling program using multiple sensors for monitoring sky radiance, atmospheric scattering coefficient profiles and other parameters related to vision through the atmosphere. With the use of very low noise 16 bit CCD cameras and an occultor designed to handle both sun and moon, these systems were further developed into the Day/Night WSI (Shields et al., 1998).

The Day/Night WSI is a 16-bit digital imaging system that acquires images of the full sky $(2 \pi$ hemisphere) under both day and night conditions in order to assess cloud fraction, cloud morphology, and radiance distribution. The WSI measures the sky radiance in approximately 185000 directions simultaneously by using a $512 \times 512 \mathrm{CCD}$ sensor. The result is a $34 \mu$ steradian field of view (FOV) in each direction, to cover the full $2 \pi$ steradian dome. Images are acquired in visible and near infrared (NIR) wavebands with filters at $450 \mathrm{~nm}$ (blue), $650 \mathrm{~nm}$ (red), and $800 \mathrm{~nm}$ (NIR) under sunlight or moonlight. Open hole (without a filter) is used for starlight and most moonlight conditions. The FWHM of the filters is $70 \mathrm{~nm}$. (Color cameras that acquire an 8 bit image in each of 3 colors are often described as 24 bit systems. The WSI aquires a 16 bit image in each of 4 colors, and could be described as a 64 bit system for comparison, although we do not usually use that nomenclature.) As a result, the WSI typically acquires onscale data over the whole sky, even near the sun.

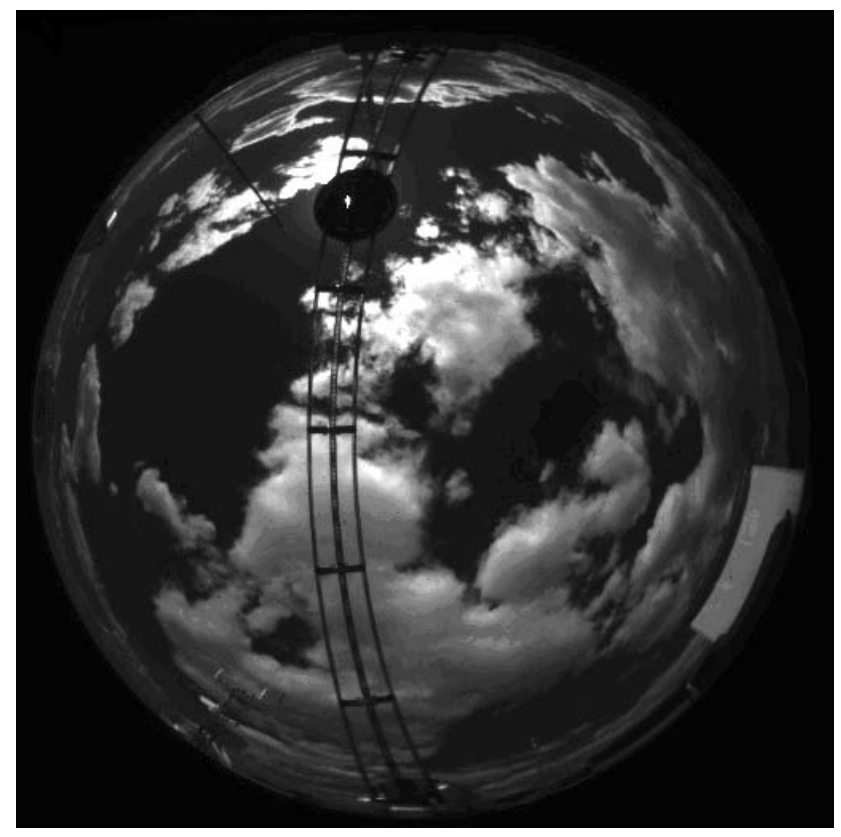

Fig. 3. Raw red image. The edge is the horizon and the center is the zenith. The arc is the shadow system.

A picture of the instrument fielded at the Oklahoma Cloud and Radiation Testbed (CART) site at SGP is shown in Fig. 2. The primary features seen in this figure are the environmental housing that protects the sensor and electronics, the optical dome, and the solar occultor that shades the optics. Even though the camera would not be damaged by direct sun radiation, this shading is desirable because it minimizes stray light especially near the sun. We feel that this feature is important for this analysis, because the signals near the sun should be less influenced by stray light than systems whose primary optics are not shaded. Figure 3 shows a daytime image. The center of the image is the zenith and the edges are the horizon.

The angular calibration of the pixels is typically first measured in the lab. Then, this calibration is further refined using star imagery. We typically select a clear night image, and then highlight a $5 \times 5$ pixels area around approximately 100 stars in the image. An interactive program models the signals within the highlighted area as a Gaussian distribution with the Point Spread Function of the system (about 0.5 pixel wide). Using the center position of the modeled Gaussian, the program then determines from star libraries which star this is, and what its actual position should be. Once this is automatically done for all selected stars, the program provides a high resolution assessment of the geometric calibration. Much of this technique was developed by our colleagues within the ARM program, with personal correspondence, and then further improved by MPL. 
The geometric calibration equations for deriving the $\mathrm{x}, \mathrm{y}$ position corresponding to a given angle for this data set are:

$X=X_{C}+\mathrm{P} \times \sin \left(\pi \phi_{\mathrm{P}} / 180\right)$

$Y=Y_{C}+\mathrm{P} \times \cos \left(\pi \phi_{\mathrm{P}} / 180\right)$

where

$\mathrm{P}=2.983 \theta-0.0006170 \theta^{2}-0.00002576 \theta^{3}+$

$0.009972 \theta \cos (\pi \phi / 90)+0.003093 \theta \sin (\pi \phi / 90)$

$\phi_{\mathrm{p}}=\phi-(-0.2967-0.0002659 \mathrm{P} \cos (\pi \phi / 90)+$

$0.001502 \mathrm{P} \sin (\pi \phi / 90))$

$\theta$ is the zenithal angle and $\phi$ is the azimutal angle. The image center pixel coordinates are $x_{C}=251.8$ and $y_{C}=254.5$. The mean residual uncertainties in $x$ and $y$ were 0.64 and 0.45 pixels respectively.

One of the capabilities of the WSI is the determination of the absolute sky radiance distribution. The fisheye lens directs the light from different directions onto different pixels in the image plane, and the signal of each pixel may be calibrated to yield a determination of the absolute sky radiance, in $\mathrm{W} / \mathrm{m}^{2} \mu \mathrm{m}$ sr, in that direction. The FOV for each pixel is approximately $34 \mu$ steradians. Thus, this radiance product is equivalent conceptually to a radiance distribution determined by a scanning radiometer, except that all radiances are acquired simultaneously and at a very high angular resolution (Shields et al., 1998).

While a full discussion of the radiometric calibration procedures has not been published in refereed literature, and is beyond the scope of this paper, an overview is given in Shields et al. (1998). A somewhat briefer overview is given here. The system is thermally stabilized, and set up with a "live zero", i.e. a positive response to no light, called a dark image. The dark images acquired at the same exposure as the field images are subtracted from the field images. Two types of linearity are measured and adjusted for. One is the non-linearity effect that results from the finite shutter timing impacts. The other is the non-linearity effect that results from the CCD response. The absolute radiance for each filter is measured at several lamp positions and/or exposure settings, so that we may have the redundancy needed to assess the relative uncertainty in the absolute calibration procedure. This response is corrected to adjust the response for individual systems to the standard filter response for the WSI. Finally, a uniformity calibration corrects for the nonuniformities within the image which are caused by the optics and the camera characteristics. Also, even though the Point Spread Function is quite tight (about 0.5 pixels), the wings of this function can cause a small stray light error. Measurements to assess this offset are taken and corrected for. A lamp traceable to NIST is used, and all electronics in the calibration room are kept in calibration.
While this calibration technique is not perfect, we feel that it should be reasonably accurate for this data set. The lamp manufacturers feel that their spectral calibration is good to $2 \%$ or better over the range of wavelengths we were using. The absolute radiance calibrations for this data set showed a self-consistency of about $0.6 \%$ (standard deviation between 4 redundant measurements in each filter, but at different exposures). Measured system non-linearities were less than $1 \%$ over dark-corrected signals of 1000 to $13000,2.5 \%$ or less over dark-corrected signals of 98 to 55235 , and were corrected for. Overall, we feel that it is reasonable to estimate the calibration uncertainty at roughly $5 \%$. At times, when a system is fielded in less than optimal conditions (e.g. the camera housings are not kept purged with dry nitrogen), the filters can degrade and the calibration will no longer apply. This did not happen for this site and data set.

Part of the analysis involved sorting the data by using the results of the cloud algorithm. Since some of the readers are perhaps familiar with cloud algorithms developed by others to use with these data, we should note that a different algorithm was used. The algorithm that was used was developed by MPL. It is based on the threshold of the ratio between the red and blue images in a similar way Long et al. (2006) describe. It has not been published, because it was in continuing development until quite recently. We plan to publish it in the future. Although an interim version of the MPL algorithm was used for this data set, review of the results show that the cloud assessments are quite good except near the sun in heavy haze. For the purposes of this article, it is perhaps sufficient to note that the sorting was verified by the authors, to make sure that those cases identified as clear and used in the analysis really were clear.

\section{Methodology and results}

The sky radiance depends directly on the aerosol load through several parameters connected with extensive and intensive aerosol properties. While previous investigations have related AOD to radiances measured in a restricted range of scattering angle to simulate the spaceborne point of view (e.g. Kaufman, 1993; Sánchez et al., 1998), here the development is focused on surface measurements.

There is a dependency between radiance along the principal plane and the aerosol optical parameters (Olmo et al., 2008). Radiance along the principal plane is affected by the amount of aerosol, related to the AOD, and the particles size, which has impact on the Ångström coefficients $\alpha$ and $\beta$ (Ångström, 1964). The impact of the AOD and $\alpha$ on the radiance over the principal plane is shown in Fig. 4. The graph shows principal planes measured with the WSI. Two different days with extreme values of $\alpha$ and different values of AOD are shown. The relationship of the radiation over the principal plane and the AOD can be seen as well as the relationship 


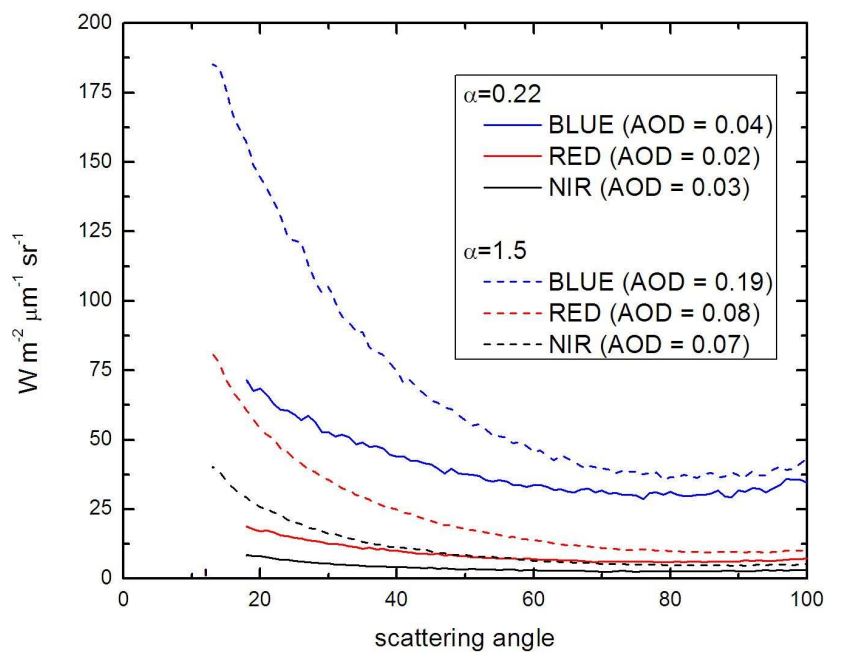

Fig. 4. Comparison of the radiance along the principal plane of the WSI varying the Ångström exponent $\alpha$ and AOD. The three wavelengths of the WSI are represented.

of the radiation over the principal plane, the wavelength and $\alpha$.

These previous works, along with the results obtained with the All-Sky Imager characterizing the atmospheric aerosol (Cazorla et al., 2008b) are the basis of this work. We also have considered the use of sky radiance in the principal plane since the obstruction of the image due to the shadow system is smaller.

The data set selected in this work comprises the period from 1 October 2001 to 29 September 2002. This data set is from a whole year so we can model the seasonal variability of the atmospheric aerosol. Using the cloud decision images processed by AOG we sorted out all the cases with clouds, to work with the clear-sky results. A visual inspection of those clear-sky images were perform to assure the quality of the data set. Images were associated with a synchronous CIMEL measurement, applying a \pm 5 min margin yielding a total of 1047 clear-sky image sets (i.e. 3 spectral images acquired in one set). These images have been used to create and validate the model.

\subsection{Retrieving the radiance over the principal plane of the sky images}

Knowing the Sun position we can locate the principal plane making the azimuthal angle equal to the Sun azimuthal angle or that angle plus $180^{\circ}$, and varying the zenith angle. The radiance over the principal plane has been extracted for the whole data set from scattering angle $1^{\circ}$ to $100^{\circ}$. The cloud decision image provided by the WSI has been used to apply a mask over the non-valid values (horizon obstruction and shadow system obstruction). The stored values from the principal plane are calibrated values, i.e. sky radiance, in

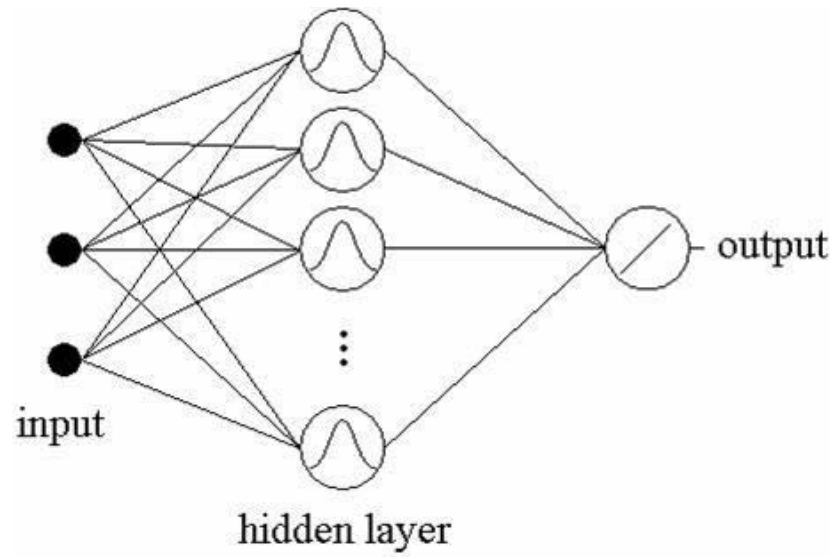

Fig. 5. RBF network topology.

$\mathrm{W} / \mathrm{m}^{2} \mu \mathrm{m} \mathrm{sr}$, for every scattering angle in the principal plane.

The wavelengths of the WSI filters have to be related with the wavelengths used to measure the direct irradiance with the CIMEL CE318. We used the nearest wavelength and, therefore the $450 \mathrm{~nm}$ filter is associated with the $440 \mathrm{~nm}$ in CIMEL, the $650 \mathrm{~nm}$ filter is associated with the $675 \mathrm{~nm}$ in CIMEL and the $800 \mathrm{~nm}$ filter is associated with the $870 \mathrm{~nm}$ in CIMEL.

\subsection{Neural networks and radial basis function networks}

According to Haykin (1994) a neural network resembles the human brain in two aspects: the knowledge is acquired by the network through a learning process, and interneuron connection strengths known as synaptic weights are used to store the knowledge. Once a neuron is set up, it can learn to emulate behaviors such as classification, pattern recognition, function approximation, control system, etc.

Neural networks have been widely used in atmospheric science recently (e.g. Gutiérrez et al., 2004) and we have experimented with them in several research applications (Alados et al., 2004, 2007; Cazorla et al., 2005, 2008b; Gil et al., 2005). The radial basis function (RBF) networks (Gutiérrez et al., 2004; Yee and Haykin, 2001) are especially suitable for function approximation. Inputs to RBF networks are the variables of the function, and the output is the function approximation.

RBF networks emerged as a variant of artificial neural networks in the late 80's. However, their roots are entrenched in much older pattern recognition techniques as for example potential functions, clustering, functional approximation, spline interpolation and mixture models (Tou and Gonzalez, 1974).

RBF networks topology is a three layer neural network, the input layer, the hidden layer and the output layer, where each hidden unit (each neuron in the hidden layer) implements a radial activated function. The output layer implements a weighted sum of hidden unit outputs. The input to a 
RBF network is nonlinear while the output is linear. Figure 5 shows a typical topology of a RBF network.

The RBF networks excellent approximation capabilities have been studied by Poggio and Girosi (1990) and Park and Sandberg (1991). Due to their nonlinear approximation properties, RBF networks are able to model complex mappings, which perceptron neural networks can only model by means of multiple intermediary layers (Haykin, 1994).

In order to use a RBF network we need to specify the hidden unit activation function, the number of processing units, a criterion for modeling a given task and a training algorithm for finding the parameters of the network. Finding the RBF weights is called network training. If we have at hand a set of input-output pairs, called a training set, we optimize the network parameters in order to fit the network outputs to the given inputs. The fit is evaluated by means of a cost function, usually the mean square error. After training, the RBF network can be used with data whose underlying statistics is similar to that of the training set.

RBF networks are characterized for the transfer function which is the Radial Basis Function (RBF). In this case input to the transfer function is the vector distance between its weight vector $\boldsymbol{w}$ and the input vector $p$, multiplied by the bias $b$

$n=\|\boldsymbol{w}-p\| b$

The transfer function for a radial basis neuron is a Gaussian function

$a(n)=\exp \left(-n^{2}\right)$

The RBF has a maximum of 1 when its input is 0 . As the distance between $\boldsymbol{w}$ and $p$ decreases, the output increases. Thus, a radial basis neuron acts as a detector that produces 1 whenever the input $p$ is identical to its weight vector $\boldsymbol{w}$. The bias $b$ allows the sensitivity of the neuron to be adjusted.

This transfer function allows a very simple training for function approximation or interpolation. Every sample in the training set creates a new neuron in the hidden layer. The weight of the connection input-neuron is set to the input value. Therefore $n$ in Eq. (5) is 0 and $a$ in Eq. (6) is 1 . The last layer gathers the hidden layer's outputs and readjusts the output to provide the correct function value. A typical input would activate several neurons (the weight is not exactly the same as the input since the input is not in the training set), i.e. $0<a<1$ for several neurons output and the final output to the network is a combination of the different neuron outputs. This feature allows to the network to interpolate the function values and, therefore learn the shape of the function. Assuming that the training set is well spread along the input range, the RBF network learns the shape of the function with the training set. An independent set, the test set, is used to evaluate the function approximation. It works like a spline interpolation with the advantage that $\mathrm{N}$-dimensional functions can be approximated easily but the disadvantage that the function is unknown.

\subsection{Development of a neural network-based model for the AOD estimation}

We have the sky radiance over the principal plane for scattering angles from 1 to $100^{\circ}$ and the Solar Zenith Angle in degrees $\left(\mathrm{SZA}^{\circ}\right)$ as inputs. Thus, we developed a RBF network model for each WSI wavelength obtaining an estimation of the AOD at 440,675 and $870 \mathrm{~nm}$.

\subsubsection{Neural network-based model}

The whole data set consists of the radiances over the principal plane of the 1047 images, the $\mathrm{SZA}^{\circ}$ at the time of the measurement and the synchronous CIMEL measurement. This set is divided randomly in two subsets, a training set using $2 / 3$ of the whole data set and a test set using $1 / 3$ of the whole data set. All values are normalized to the range $[0,1]$, i.e. the values are rescaled to that range where the minimum and maximum values correspond to 0 and 1 respectively. Inputs (radiances over the principal plane and $\mathrm{SZA}^{\circ}$ ) and outputs (AODs) are normalized. During the training every measurement is used to adjust the internal values of the neural network (the weights) so the output is the desired variable amount, i.e. the AOD corresponding to the wavelength we are trying to estimate. Once the network is trained we use the test set to evaluate the performance of the network. The coefficient of determination $\left(R^{2}\right)$ calculated between the AOD measured with the CIMEL and the values estimated with the network using the test set is our estimator of the performance.

The performance depends on the selection of the training and test sets. These sets are created randomly out of the whole data set. Hence we repeat the process nine times and select the best partition, i.e. the one that yields the best performance.

\subsubsection{Input selection algorithm}

The selection of the scattering angles used as inputs is done by means of a greedy algorithm (Cormen et al., 2001). The greedy algorithms are iterative algorithms that build a string solution getting the best item every loop. The information to calculate the AOD is in the in the radiation over the principal plane (scattered radiation), but not all the scattering angles are necessary as it was noticed in our previous work (Cazorla et al., 2008b). The first iteration of the algorithm creates 100 RBF networks using the radiance at only one of the scattering angles. All of them are evaluated using the $R^{2}$ and the best one is added to the solution. The second iteration of the algorithm creates 99 networks using the radiance at the best scattering angle of the previous iteration and the radiance at a different scattering angle. Once again, the best one is added to the solution. This process is repeated until the $R^{2}$ decreases, and this means that no more scattering angles are needed. 

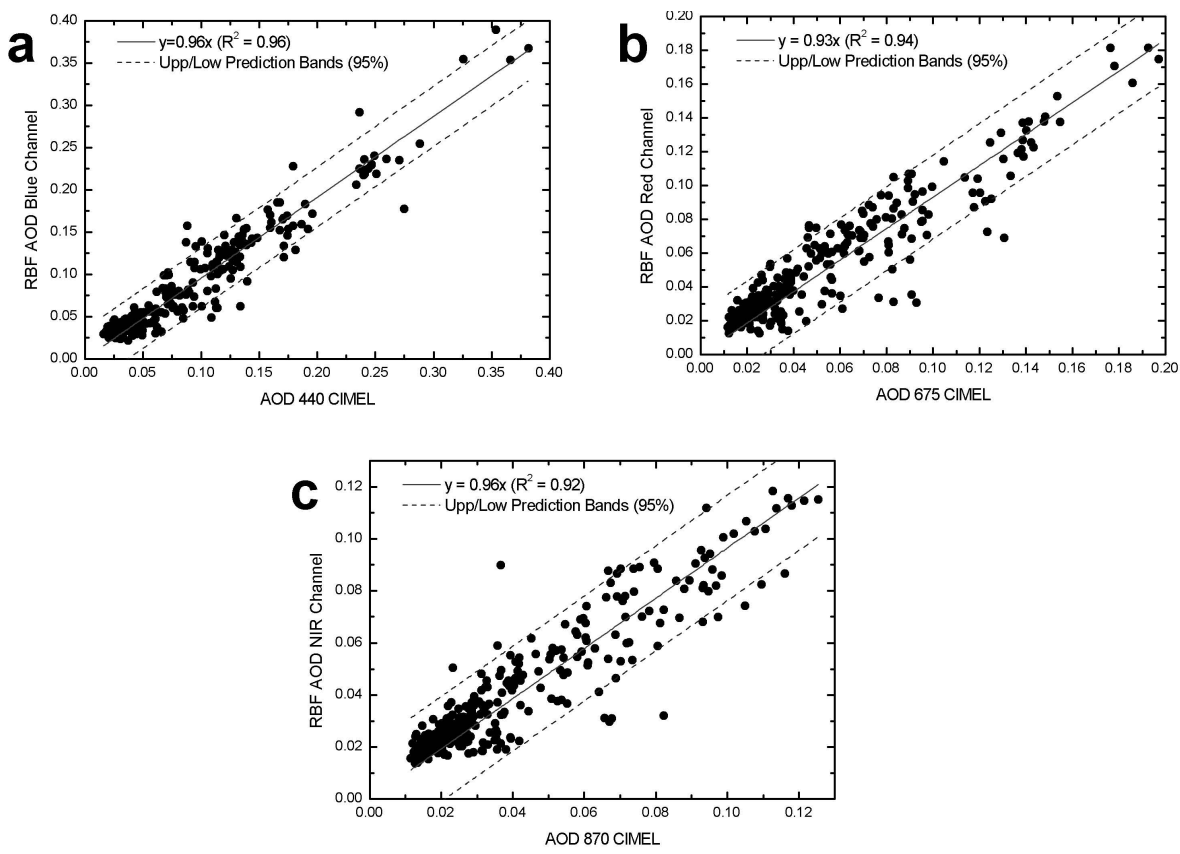

Fig. 6. Scatter plot of estimated AOD values from the WSI versus values calculated from the CIMEL for (a) AOD at $440 \mathrm{~nm}$, (b) AOD at $675 \mathrm{~nm}$ and (c) AOD at $870 \mathrm{~nm}$. The line represents the linear fit through zero and the dashed lines are the upper and lower prediction bars at $95 \%$.

Table 1. Statistical results of the validation for the radial basis networks for estimation of AOD at $440 \mathrm{~nm}$, AOD at $670 \mathrm{~nm}$ and AOD at $870 \mathrm{~nm}$. The column b represents the slope of the linear fitting through zero of the data, $R^{2}$ is the coefficient of determination, MBD is the mean bias deviation and RMSD is the root mean squared deviation

\begin{tabular}{lllllll}
\hline Channel & Set size & Scattering angle & $\mathrm{B}$ & $\mathrm{R}^{2}$ & $\mathrm{MBD}(\%)$ & $\mathrm{RMSD}$ \\
\hline BLUE (AOD440) & 930 & 37 & 0.96 & 0.96 & -2 & 0.05 \\
RED (AOD675) & 968 & 71 & 0.93 & 0.94 & -1 & 0.07 \\
NIR (AOD870) & 973 & 83 & 0.96 & 0.92 & 3 & 0.06 \\
\hline
\end{tabular}

During the process we applied a mask to eliminate the measurements with non valid values (obstruction due to the horizon or shadow system). As a result, the final data set may vary depending on the scattering angles used.

\subsubsection{Results}

Every wavelength has an independent model. The inputs and, therefore the training and test sets, are different for each AOD estimation.

The greedy algorithm selected only one scattering angle for each AOD model. For the blue WSI channel $(450 \mathrm{~nm}$ associated to the $440 \mathrm{~nm}$ AOD), it selected the $37^{\circ}$ scattering angle. Therefore the model has two inputs: the radiance of the sky at that scattering angle over the principal plane and the $\mathrm{SZA}^{\circ}$. 117 measurements had to be eliminated from the original 1047 measurements due to shadow system obstruc- tion, so the model was created from the remainder of this set with 930 measurements.

The greedy algorithm for the model with the red WSI channel $(650 \mathrm{~nm}$ associated to the $675 \mathrm{~nm}$ AOD) selected the $71^{\circ}$ scattering angle. The number of valid measurements after applying the mask is 968 .

The greedy algorithm for the model with the NIR WSI channel ( $800 \mathrm{~nm}$ associated to the $870 \mathrm{~nm}$ AOD) selected the $83^{\circ}$ scattering angle. The number of valid measurements is 973 in this case.

Figure $6 a, b$ and $c$ show estimated values of AOD at 440,675 and $870 \mathrm{~nm}$ respectively versus calculated values of AOD with the CIMEL at those wavelengths. The analysis has been done over the test set. The linear fit was forced through zero so the slope provides information about the over- or underestimation associated with the model. The coefficient of determination provides an evaluation of the experimental 


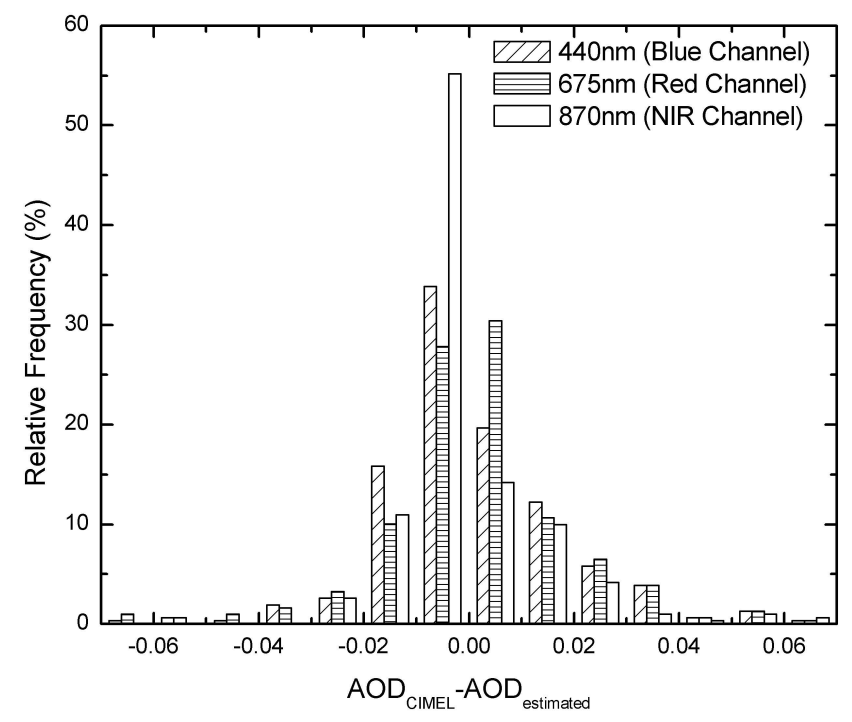

Fig. 7. Histogram of the differences between calculated (from CIMEL measurements) and estimated values for AOD at $440 \mathrm{~nm}$, $\mathrm{AOD}$ at $675 \mathrm{~nm}$ and $\mathrm{AOD}$ at $870 \mathrm{~nm}$.

variance explained by the model. The root mean square deviation (RMSD):

$\mathrm{RMSD}=\sqrt{\frac{\sum_{i=1}^{n}\left(y_{i}-x_{i}\right)^{2}}{N}}$

and the mean bias deviation (MBD):

$\operatorname{MBD}(\%)=100 \times \frac{\frac{1}{N} \sum_{i=1}^{n}\left(y_{i}-x_{i}\right)}{\frac{1}{N} \sum_{i=1}^{n} x_{i}}$

have been also evaluated as quality estimators. These quality estimators allow us to evaluate the differences between the experimental data and the model and the presence of a systematic over- or underestimation. Table 1 shows the statistics for the three models. Figure 7 show histograms of the differences between measured and estimated AOD at 440, 675 and $870 \mathrm{~nm}$.

As we can see in Fig. 6a and Table 1, 96\% of the data variance is explained by the model that estimates the AOD at $440 \mathrm{~nm}$. MBD and the slope of the linear fit reveal a slight systematic underestimation. Figure 7 shows a histogram of the differences between the calculated and estimated values. It reveals that $81 \%$ of the estimated AOD values at $440 \mathrm{~nm}$ had a deviation less than 0.01 with respect to the CIMEL result which is the AERONET AOD estimated uncertainty (Holben et al., 1998).

Figure $6 \mathrm{~b}$ and Table 1 reveal that $94 \%$ of the data variance is explained by the model that estimates the AOD at $675 \mathrm{~nm}$.
MBD and the slope of the linear fit also indicate a slight systematic underestimation. Figure 7 shows that almost $80 \%$ of the estimated AOD at $675 \mathrm{~nm}$ has a deviation less than 0.01 .

Finally, Fig. $6 \mathrm{c}$ and Table 1 reveal that $92 \%$ of the data variance is explained by the model that estimates the AOD at $870 \mathrm{~nm}$. While MBD suggests a slight overestimation, the slope of the linear fit indicates an underestimation. Figure 7 shows that $90 \%$ of the estimated AOD at $870 \mathrm{~nm}$ has a deviation less than 0.01 .

Figure $6 \mathrm{a}, \mathrm{b}$ and $\mathrm{c}$ reveal that the data set is not homogeneously distributed along the whole range of values. There are a lot of points with low AOD and very few with higher AOD. This can explain the slight systematic underestimation of the model. The linear fit is forced to zero and there are a lot of points close to zero, but the very few values far from the zero introduce a variance that, in this case makes the slope be slightly below 1 .

The coefficient of determination decreases when we estimate AOD at longer wavelengths. This can be because of the difference between the central wavelength of the filters of the WSI and the CIMEL increases with the wavelength. That is, the AOD at $440 \mathrm{~nm}$ is estimated with measurements at $450 \mathrm{~nm}(10 \mathrm{~nm}$ of difference), the difference is $25 \mathrm{~nm}$ for AOD at $675 \mathrm{~nm}$ and it is $70 \mathrm{~nm}$ for AOD at $870 \mathrm{~nm}$. In other words, at 440 and $675 \mathrm{~nm}$ there is an overlapping of the filters because the FWHM of the WSI filters is $70 \mathrm{~nm}$, but at $870 \mathrm{~nm}$ the filters do not overlap, hence this can produce a decrease in performance.

\subsection{Estimation of the Ångström exponent $\alpha$}

Two different approaches have been tested to estimate $\alpha$. First, we use the same procedure as in AERONET using the AODs estimated with the neural networks as seen in Sect. 3.3, and $\beta$ is also estimated. Secondly, a new neural network has been trained using the calculated $\alpha$ by AERONET. The AERONET algorithm calculates $\alpha$ using a different interval of wavelengths. The interval $440-870 \mathrm{~nm}$ includes the values we estimate, and therefore this is the interval used to compare the results in both approaches.

For the first method, Fig. 8a shows estimated versus calculated values of $\alpha$ with the CIMEL in the interval $440-870 \mathrm{~nm}$ using the standard AERONET procedure. Figure 8c shows the histogram of the differences between calculated and estimated $\alpha$. Figure 8 a reveals that $63 \%$ of the data are explained by the model that estimates $\alpha$. Figure $8 \mathrm{c}$ shows that $48 \%$ of the estimated $\alpha$ has a deviation less than 0.1 , which is the estimated uncertainty in the AERONET procedure for $\alpha$ calculation (Holben et al., 1998).

The $\alpha$ estimation is affected by the error introduced in the AOD estimation. The AOD at $870 \mathrm{~nm}$ introduces an error in the calculation of $\alpha$ by linear fitting of $\ln (\mathrm{AOD})$ vs wavelength. For this reason, we tried a new neural network-based model using RBF networks to estimate the value of $\alpha$ using the radiance over the principal plane of the sky images for the 

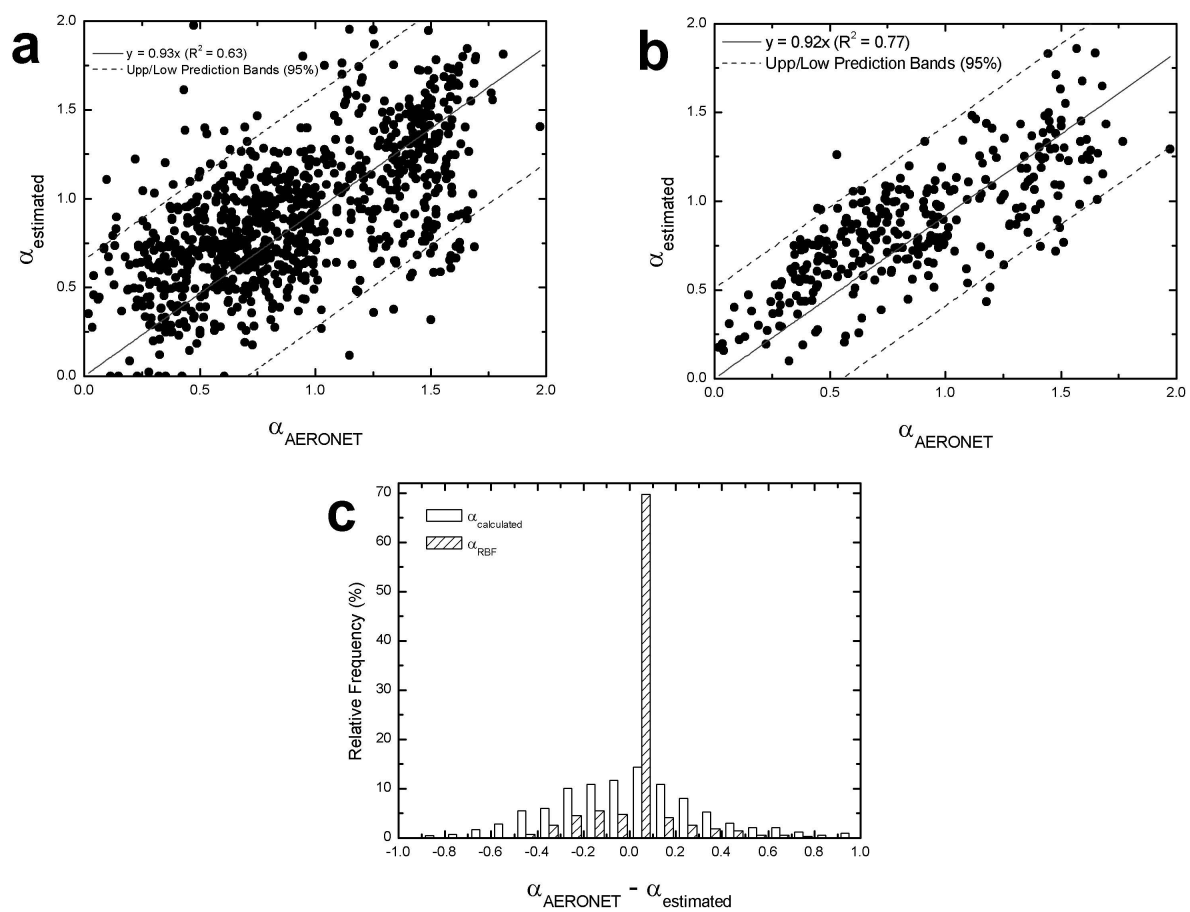

Fig. 8. Scatter plot of estimated versus measured values for $\alpha(440-870 \mathrm{~nm})$ (a) using the AERONET standard procedure and (b) using a neural network-based model with RBFs. (c) Histogram of the differences between measured and estimated values for $\alpha$ (440-870 $\mathrm{nm}$ ) for both methods.

three wavelengths. The inputs for this model are the same for the estimation of the AOD together, i.e. we combined the radiance at different scattering angles over the principal plane for the three wavelengths, and the SZA ${ }^{\circ}$. The model is trained and validated to calculate $\alpha$ in the interval 440$870 \mathrm{~nm}$ in the same way the model for the AODs were created. Figure $8 \mathrm{~b}$ shows estimated versus CIMEL calculated values of $\alpha$ in the interval $440-870 \mathrm{~nm}$ using this method. Figure $8 \mathrm{c}$ shows the histogram of the differences between measured and estimated $\alpha$. Figure $8 \mathrm{~b}$ reveals that $77 \%$ of the data are explained by the model that estimates $\alpha$. Figure 8c shows that $84 \%$ of the estimated $\alpha$ has a deviation less than 0.1 , which is the estimated uncertainty in the AERONET procedure for $\alpha$ calculation. This represents a clear improvement in the estimation of $\alpha$ from WSI images.

Even though the uncertainty in the estimation of $\alpha$ is large with the standard method, the estimation is still useful for the interpolation of the AOD at different wavelengths. We have tested it calculating the AOD at $500 \mathrm{~nm}$ with the $\alpha$ and $\beta$ estimated with the first method using Ångström Law (Ångström, 1964) and compared it with the AOD at $500 \mathrm{~nm}$ obtained from CIMEL CE318 measurements. Figure 9 shows estimated values of AOD at $500 \mathrm{~nm}$ versus calculated values of AOD with the CIMEL. $96 \%$ of the data variance is explained by the model that estimates the AOD at $500 \mathrm{~nm}$. As we can see, the use of this estimation yields a very good estimation of AOD in different wavelengths (one of the main usefulness

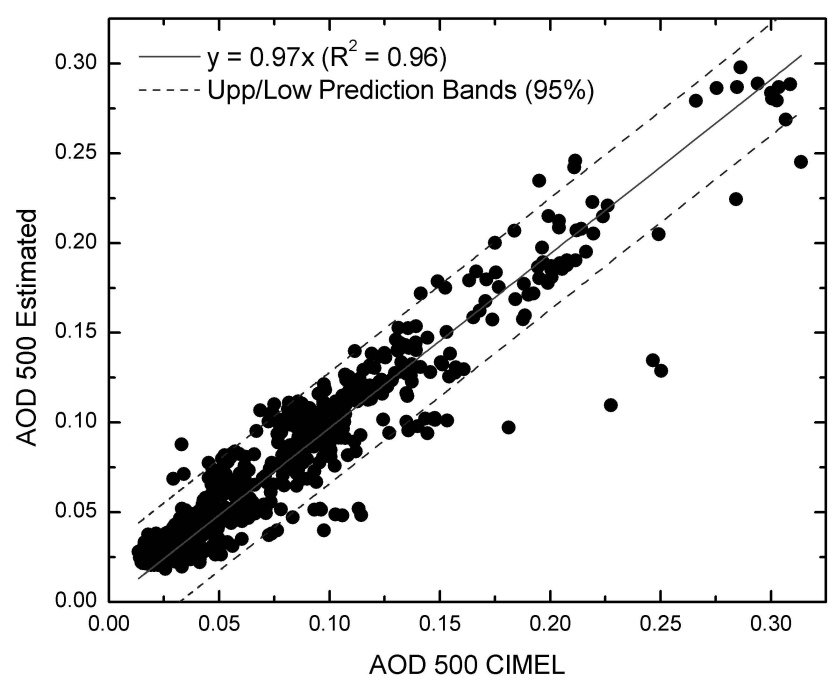

Fig. 9. Scatter plot of estimated versus measured values for AOD at $500 \mathrm{~nm}$. The estimation has been done using $\alpha$ and $\beta$ calculated with the standard AERONET procedure with the estimated values of AOD with the neural network-based model.

of $\alpha$ ). However, if we need a more precise estimation of $\alpha$, for example as input in an inversion model, we also have the most accurate estimation using the neural network-based model. 


\section{Conclusions}

Three neural network-based models using RBF networks has been created to estimate the value of the AOD at three different wavelengths using the radiance over the principal plane of the sky images from the calibrated sky imager WSI. The correlation constants are close to unity and the number of cases within measurement error is very large. Only one scattering angle per channel has been used: 37,71 and $83^{\circ}$ corresponding to the blue, red and NIR channel respectively. The estimation of $\alpha$ has been performed in two ways. First, it has been calculated using the standard procedure in AERONET using the AODs estimated with the neural network ( $\beta$ is also calculated) and secondly, it has been estimated with a new neural network-based model using RBF networks. Inputs to this RBF network are the radiances in the same scattering angles used for the AOD models.

The three AOD models provide an estimation that, according to validation, is inside the nominal error of the AERONET $( \pm 0.01)$ in approximately $80 \%$ for the blue and red channels and $90 \%$ for the NIR channel. In all cases the models explain up to $92 \%$ of the variance of the experimental data. The coefficient of determination decreases when we estimate AOD at longer wavelengths. This can be caused by the difference between the central wavelength of the filter in the sky imager and the CIMEL. This difference is larger with longer wavelengths and, therefore, the overlap of the wavelength decreases and so the performance. Nevertheless, all estimations have a coefficient of determination over 0.92 .

Concerning the scattering angles selected with the greedy algorithm, these reveal that to estimate the AOD at $450 \mathrm{~nm}$ (blue) it is necessary to use an angle close to the sun. The estimation of the AOD at $870 \mathrm{~nm}$ (NIR) requires an angle farther from the sun. At $675 \mathrm{~nm}$ the behavior can be catalogued as in between of the behavior presented in the other two wavelengths. The reduction of angles needed respect to the previous work can be explained by the character of the measurements since they are calibrated radiances while the previous work used pixel counts.

The $\alpha$ estimation using the AERONET method is affected by the cumulative error of all the AOD estimations. However, almost $50 \%$ of the data are inside the nominal error of the AERONET program for $\alpha$ calculation using the standard procedure in AERONET. The neural network-based model for $\alpha$ estimation increases the explanation of the data to $63 \%$ and the data inside the nominal error is increased to $77 \%$. The neural network process is complex but increases substantially the estimation. The neural network model forces the result to be the same as that estimation of $\alpha$ for the interval $440-870 \mathrm{~nm}$.

The results are promising in the sense that it seems to be feasible that a sky imager can estimate the AOD and the algorithm could be applied in the field. Furthermore, we believe that this model might be applied to different WSIs in different locations without a new training process since all the
WSIs have an absolute radiance calibration and this proposed model directly relates spectral radiances in fixed geometries with AOD and $\alpha$, thus the underlying statistics of the data is similar to that of the training set used in this work. Nevertheless, this validation with different WSI dataset in different location might be undertaken in the future. The two methods for the $\alpha$ estimation differ, however we consider that the standard AERONET procedure is simple and useful for the interpolation of AODs at different wavelengths. Nevertheless, the more complex and accurate one (the neural network-based one) might be better as input for inversion model algorithms.

Acknowledgements. This work was supported by the Centro de Investigación Científica y Tecnológica (CICYT) of the Spanish Ministry of Science and Technology through projects CGL200766477-C02-01 and CSD2007-00067 and the Andalusian Regional Government through project P06-RNM-01503 and P08-RNM3568). First author has been funded by the Andalusian Regional Government and his research stay at University of California at San Diego has been also funded by the Andalusian Regional Government. We are also especially thankful to the principal investigator of the AERONET site at SGP, Rick Wagener and the collaboration of the US Department of Energy as part of the Atmospheric Radiation Measurement Program Climate Research Facility.

Edited by: W. Ward

\section{References}

Alados, I., Mellado, J. A., Ramos, F., and Alados-Arboledas, L.: Estimating UV erythemal irradiance by means of neural networks, Photochem. Photobiol., 80(2), 351-358, 2004.

Alados, I., Gomera, M. A., Foyo-Moreno, I., and AladosArboledas, L.: Neural network for the estimation of UV erythemal irradiance using solar broadband irradiance, Int. J. Climatol., 27, 1791-1799, 2007.

Ångström, A.: The parameters of atmospheric turbidity. Tellus 16, 64-75, 1964.

Cazorla, A., Olmo, F. J., and Alados-Arboledas, L.: Determinación de la cubierta nubosa en imágenes de cielo mediante un perceptrón multicapa, in: Determination of cloud cover on sky images by means of Multilayer Perceptron, edited by: Rojas, I., Pomares, H., Actas del Simposio de Inteligencia Computacional, SICO2005 (IEEE Computational Intelligence Society, SC), Thomson, Spain, 27-30, 2005.

Cazorla, A., Olmo, F. J., and Alados-Arboledas, L.: Development of a sky imager for cloud cover assessment, J. Opt. Soc. Am. A, 25(1), 29-39, 2008a.

Cazorla, A., Olmo, F. J., and Alados-Arboledas, L.: Using a sky imager for aerosol characterization, Atmos. Environ., 42(11), 2739-2745, 2008b.

Cormen, T. H., Leiserson, C. E., and Rivest, R. L.: Introduction to algorithms, MIT Press, Cambridge, MA, USA, 2001.

Dubovik, O., Holben, B. N., Lapyonok, T., Sinyuk, A., Mishchenko, M. I., Yang, P., and Slutsker, I.: Non-spherical aerosol retrieval method employing light scattering by spheroids, Geophys. Res. Lett., 29(10), Art. No. 1415, 2002. 
Dubovik, O., Sinyuk, A., Lapyonok, T., Holben, B. N., Mishchenko, M., Yang, P., Eck, T. F., Volten, H., Muñoz, O., Veihelmann, B., van der Zande, W. J., Leon, J. F., Sorokin, M., and Slutsker, I.: Application of spheroid models to account for aerosol particle nonsphericity in remote sensing of desert dust, J. Geophys. Res., 111, D11208, doi:10.1029/2005JD006619, 2006.

Foster, P., Ramaswamy, V., Artaxo, P., Berntsen, T., Betts, R., Fahey, D.W., Haywood, J., Lean, J., Lowe, D.C., Myhre, G., Nganga, J., Prinn, R., Raga, G., Schulz, M., Van Dorland, R. Changes in Atmospheric Constituents and in Radiative Forcing. In: Climate Change 2007: The Physical Science Basis. Contribution of Working Group I to the Fourth Assessment Report of the Intergovernmental Panel on Climate Change, edited by: Solomon, S., Qin, D., Manning, M., Chen, Z., Marquis, M., Averyt, K. B., Tignor, M., and Miller, H. L., Cambridge University Press, Cambridge, UK and New York, NY, USA, 2007.

Gil, J. E., Cazorla, A., Olmo, F. J., Alados-Arboledas, L.: Experimental set up to study the cloud radiative effects on UVB at Granada (Spain), edited by: Richter, A. K., European Geosciences Union, General Assembly, vol. 1, EGU05-A-00320; AS1.08.1WE2P-0059, 2005.

Gutiérrez, J. M., Cano, R., Cofiño, A. S., and Sordo, C.: Redes Probabilísticas y Neuronales en las Ciencias Atmosféricas (Probabilistic and Neural Netwoks on Atmospheric Sciences). Ministerio de Medio Ambiente, Dirección General del Instituto Nacional de Meteorología, 2004.

Haykin, S.: Neural Networks: A comprehensive Foundation. MacMillan, New York, USA, 695 pp., 1994.

Holben, B. N., Eck, T. F., Slutsker, I., Tanre, D., Buis, J. P., Setzer, A., Vermote, E., Reagan, J. A., Kaufman, Y. J., Nakajima, T., Lavenu, F., Jankowiak, I., and Smirnov, A.: AERONET-A federated instrument network and data archive for aerosol characterization, Remote Sens. Environ., 66(1), 1-16, 1998.

IPCC, 2007: Climate Change 2007: The Physical Science Basis, Contribution of Working Group I to the Fourth Assessment Report of the Intergovernmental Panel on Climate Change, edited by: Solomon, S., Qin, D., Manning, M., Chen, Z., Marquis, M., Averyt, K. B., Tignor, M., and Miller, H. L., Cambridge University Press, Cambridge, United Kingdom and New York, NY, USA, 996 pp., 2007.

Kaufman, Y. J.: Aerosol optical thickness and atmospheric path radiance, J. Geophys.1 Res.-Atmos., 98(D2), 2677-2692, 1993.

Kaufman, Y. J., Tanré, D., Holben, B. N., Mattoo, S., Remer, L. A., and Eck, T. F.: Aerosol radiative impact on spectral solar flux at the surface, derived from principal plane sky measurements, J. Atmos. Sci., 59(3), 635-646, 2002.
Long, C. N., Sabburg, J. M., Calbó, J., and Pagès, D.: Retrieving cloud characteristics from ground based daytime color all-sky images, J. Atmos. Ocean. Technol., 23(5), 633-652, 2006.

Lyamani, H., Olmo, F. J., and Alados-Arboledas, L.: Saharan dust outbreak over south-eastern Spain as detected by sun photometer, Atmos. Environ., 39, 7276-7284, 2005.

Lyamani, H., Olmo, F. J., Alcantara, A., and Alados-Arboledas, L.: Atmospheric aerosols during the 2003 heat wave in southeastern spain I: spectral optical depth, Atmos. Environ., 40, 6453-6464, 2006a.

Lyamani, H., Olmo, F. J., Alcantara, A., and Alados-Arboledas, L.: Atmospheric aerosols during the 2003 heat wave in southeastern spain II: Microphysical columnar properties and radiative forcing, Atmos. Environ., 40, 6465-6476, $2006 \mathrm{~b}$.

Olmo, F. J. and Alados-Arboledas, L.: Pinatubo eruption effects on solar radiation at Almería, Tellus 47B, 602-606, 1995.

Olmo, F.J., Quirantes, A., Lara, V., Lyamani, H., and AladosArboledas, L.: Aerosol optical properties assessed by an inversion method using the solar principal plane for non-spherical particles, J. Quant. Spectros. Radiat. T., 109(8), 1504-1516, 2008.

Park, J. and Sandberg, J. W.: Universal approximation using radial basis functions network, Neural Comp., 3, 246-257, 1991.

Poggio, T. and Girosi, F.: Networks for approximation and learning, Proc. IEEE, 78(9), 1481-1497, 1990.

Sabburg, J.: Quantification of Cloud Around The Sun And Its Correlation With Global UV Measurement, PhD Thesis, Queensland University, 2000.

Sánchez, C., Olmo Reyes, F. J., and Alados-Arboledas, L.: Determination of aerosol optical thickness from measurements of spectral sky radiance. J. Aerosol Sci., 29(10), 1199-1211, 1998.

Shields, J. E., Johnson, R. W., Karr, M. E., Wertz, J. L.: Automated Day/Night Whole Sky Imager for field assessment of cloud cover distributions and radiance distributions. Proceedings of the 10th Symposium on Meteorological Observations and Instrumentations, Phoenix, AZ, USA, Am. Meteorol. Soc., Boston, MA, USA, 165-170, 1998.

Tou, J. T. and Gonzalez, R. C.: Pattern Recognition Principles. Addison-Wesley, Reading, MA, USA, 377 pp., 1974.

Yee, P. V. and Haykin, S.: Regularized Radial Basis Function Networks: Theory and Applications. Wiley, New York, USA, 191 pp., 2001. 